\title{
Spatiotemporal Mapping of Salt Marshes in the Intertidal Zone of China during 1985-2019
}

\author{
Guangwei Chen, ${ }^{1}$ Runjie Jin $\mathbb{D}^{1},{ }^{1}$ Zhanjiang Ye ${ }^{\mathbb{D}},{ }^{1} \mathrm{Qi}$ Li, ${ }^{1}$ Jiali Gu ${ }^{1},{ }^{1,2}$ Min Luo, \\ Yongming Luo, ${ }^{3}$ George Christakos, ${ }^{1}$ James Morris, ${ }^{4}$ Junyu He $\mathbb{D}^{1,2}$ Dan Li ${ }^{10},{ }^{1}$ \\ Hengwei Wang $\mathbb{D}^{1}{ }^{1}$ Li Song $\mathbb{D}^{1},{ }^{1}$ Qiuxuan Wang, ${ }^{1}$ and Jiaping $W u \mathbb{D}^{1}$ \\ ${ }^{1}$ Ocean College, Zhejiang University, Zhoushan 316021, China \\ ${ }^{2}$ Ocean Academy, Zhejiang University, Zhoushan 316021, China \\ ${ }^{3}$ Institute of Soil Science, Chinese Academy of Sciences, Nanjing 210008, China \\ ${ }^{4}$ Baruch Institute for Marine \& Coastal Sciences, University of South Carolina, SC 29208, USA
}

Correspondence should be addressed to Jiali Gu; jialigu@zju.edu.cn and Jiaping Wu; jw67@zju.edu.cn

Received 20 July 2021; Accepted 12 December 2021; Published 20 January 2022

\begin{abstract}
Copyright () 2022 Guangwei Chen et al. Exclusive Licensee Aerospace Information Research Institute, Chinese Academy of Sciences. Distributed under a Creative Commons Attribution License (CC BY 4.0).
\end{abstract}

\begin{abstract}
This study mapped the areal extent, identified the species composition, and analyzed the changes of salt marshes in the intertidal zone of China during the period 1985-2019. With the aid of the cloud platform of the Google Earth Engine, we selected Landsat 5/ 8 and Sentinel-2 images and used the support vector machine classification method to extract salt marsh information for the years of 1985, 1990, 1995, 2000, 2005, 2010, 2015, and 2019. Seven major species of salt marshes: Phragmites australis, Suaeda spp., Spartina alterniflora, Scirpus mariqueter, Tamarix chinensis, Cyperus malaccensis, and Sesuvium portulacastrum were identified. Our results showed that salt marshes are mainly distributed in Liaoning, Shandong, Jiangsu, Shanghai, and Zhejiang, with varying patterns of shrinking, expansion, or wavering in different places. The distribution of salt marshes has declined considerably from 151,324 ha in 1985 to 115,397 ha in 2019 , a drop of $23.7 \%$. During the same period, the area of native species has dropped $95.4 \%$ from 77,741 ha to 3,563 ha for Suaeda spp. and $45.1 \%$ from 60,511 ha to 33,193 ha for P. australis; on the contrary, the area of exotic species, S. alterniflora, has exhibited a sharp rise from just 99 ha to 67,527 ha. For the past 35 years, the driving factors causing salt marsh changes are mainly land reclamation, variations in water and sand fluxes, and interspecific competition and succession of salt marsh vegetation. These results provide fundamental reference information and could form the scientific basis for formulating policies for the conservation and utilization of salt marsh resources in China.
\end{abstract}

\section{Introduction}

Salt marshes are often found in the transitional zone between terrestrial and marine environment, which are inhabited by halophyte communities [1], and they grow on a variety of substrates, ranging from silt to gravel [2]. Salt marshes provide a range of ecosystem benefits, such as coastal resilience, denitrification, filtration of pollutants, nursery habitat, food supply, and nutrient cycling. As one of the important Blue carbon ecosystems, salt marsh has great capacity in carbon storage and sequestration [3], playing a critical role in global change mitigation/adaptation. Despite such important functions and benefits, global salt marshes have been declining due to land development, reduced sediment supply, and/or sea-level rise, etc. [3-5].
However, in China, as an exotic species of salt marshes, Spartina alterniflora (S. alterniflora) competed with native plants, threatening native ecosystems and coastal aquaculture and causing the decline in local biodiversity [5-10]. Subsequently, the invasion and control of exotic species have become a hot topic and drawn wide attention from ecoenvironmental community all over the world [11]. Information on the spatial distribution, areal extent, and species composition of salt marshes across a wide range of time is of critical importance to governmental agencies, science communities, and citizens, whereas despite national and international concerns, few data of salt marshes in China have been publicly available at national scale $[12,13]$.

Remote sensing (RS) has been widely used as a useful tool for mapping vegetation and monitoring vegetation 
dynamics and biodiversity conservation at a large scale [14-16]. Technical barriers to national scale survey and mapping have been greatly reduced in recent years with the availability of free, postprocessed satellite, and aerial imagery with national to global coverage. Moreover, an increasing number of studies have adopted object-based image analysis (OBIA) to identify $S$. alterniflora $[6,17,18]$, and OBIA and support vector machine (SVM) classification have been proven to be promising tools for mapping the invasion of S. alterniflora [18]. Google Earth Engine (GEE) has enabled time-series analysis in freshwater wetland change [20]. Cloud computing and high-power computing are frequently employed in time-series studies to quantify ecological processes and land use/cover change [21-24]. With the development of unmanned airborne vehicle (UAV) technology, it is possible to acquire high/ultra-high spatial resolution images to verify the species of salt marshes at the patch scale. What is more, the characteristics of quick flight deployments and feasible flight timing of UAV make it ideal in monitoring salt marshes change in intertidal zone where periodically inundated vegetation has a limited exposure period [25].

In China, previous studies about S. alterniflora invasion and salt marshes change have focused on local regions, failing to provide and update the salt marsh information in a timely manner, even though this information is critical for supporting resources management, protecting important habitats of endangered species, and ensuring ecological security in response to global change $[26,27]$. The resulting information deficiency has limited decision-making regarding the sustainable ecosystem management of coastal wetlands and the socioeconomic development of coastal regions. In view of these considerations, the goal of the present study is to generate the detailed information on salt marshes, including native and exotic species during 19852019 in the intertidal zone of China by using a quantitative approach based on Landsat, Sentinel-2, and UAV imagery.

\section{Materials and Methods}

2.1. Study Area. Salt marshes are widely distributed along coast; thus, the study area covers the whole intertidal zone of China, ranging from $18^{\circ} \mathrm{N}-41^{\circ} \mathrm{N}$ in latitude and $108^{\circ} \mathrm{E}-$ $124^{\circ} \mathrm{E}$ in longitude, crossing warm temperate, subtropica, 1 and tropical climatic zones. In this study, the coastline was manually adjusted based on the natural and man-made coastline data of Open Street Map (https://osm-boundaries $. \mathrm{com} /$ ) and remote sensing images. We have designated a $10 \mathrm{~km}$ buffer zone along the coastline to delineate the potential areas of intertidal salt marshes [28]. The common salt marsh species in coastal China include S. alterniflora, Phragmites australis (P. australis), Tamarix chinensis (T. chinensis), Scirpus spp., Suaeda spp., Cyperus malaccensis (C. malaccensis), and Sesuvium portulacastrum (S. portulacastrum) $[6,13,29,30]$. P. australis, Suaeda spp., and T. chinensis are mainly distributed in northern China such as Liao River Delta and Yellow River Delta. The invasive species S. alterniflora is mainly distributed in the coastal areas of eastern China, including Jiangsu, Shanghai, Zhejiang, and Fujian and has also appeared scattered in Liaoning, Hainan, and Taiwan. Scirpus spp. is mainly distributed in Shanghai, Jiangsu, and Hangzhou Bay. C. malaccens is mainly distributed in South China regions such as Guangdong and Guangxi.

2.2. Data Collection. A large number of satellite images, such as Sentinel and Landsat series, are publicly available and cover the study area in both time and space. In this study, we processed the Landsat Thematic Mapper (TM)/Operational Land Imager (OLI) and Sentinel-2 images on GEE cloud computing platform. Multispectral Landsat 5/8 and Sentinel-2 have $30 \mathrm{~m}$ and $10 \mathrm{~m}$ spatial resolution, respectively. We selected a total of 174 scenes of Landsat 5 images from 1985 to 2011, 35 scenes of Landsat 8 images from 2014 to 2016, and 79 scenes of Sentinel-2 images in 2019 in this study (Tables S1, Tables S2). We used all available standard Landsat L1T and Sentinel-2 L1C data. Multitemporal images in specific locations were selected for the better separation of salt marshes from other species according to the phenological stages and tidal level. Generally, vegetation in the late growing season may show significant spectral differences. From July to September, it is the most luxuriant season for salt marshes, and from September to November, it has the highest biomass. Therefore, selecting the images between July and November is beneficial for salt marsh identification and mapping. Tidal flooding can reduce the spectral reflectance and add noise to the salt marsh classification. Then, images with low tides were considered a better choice. In other words, salt marshes located in lower intertidal zones could be better identified at low tide [31]. Thick cloud cover and heavy fog also reduce the quality of images. We selected images that had the cloud cover less than $10 \%$ to maintain data quality; however, best available images for some areas still had thin clouds, which would influence the surface reflectance of different land covers. Thus, pixels that were identified as cloud or cloud shadow by the FMask algorithm [32] were excluded from the image stacks to avoid errors. As tidal stages affect saltmarsh interpretation of remote sensing images [33], we looked through all the cloud-free scenes and manually selected relative low-tide scenes by overlaying the scenes. In some regions, all available images in a certain year could not meet the above criteria. Instead, we selected images acquired within the neighboring year to maintain the image quality for the target area.

2.3. Methods to Identify Salt Marshes in Intertidal Zone. The SVM is based on statistical learning theory and classifies data by determining a set of support vectors that are members of the labeled training data samples. The main objective of SVM is to find an optimal hyperplane for the classification of new data points [34]. This method has been widely used to produce land use/cover products. We conducted preprocessing and supervised classification for all images on the GEE platform. The SVM model can be applied to classification that was trained to use randomly selected pixels of different salt marsh species from Landsat 5/8 and Sentinel-2 images (Figure 1). To identify salt marsh species better, two widely used vegetation indices and four water-related spectral indices were applied in the SVM model: 

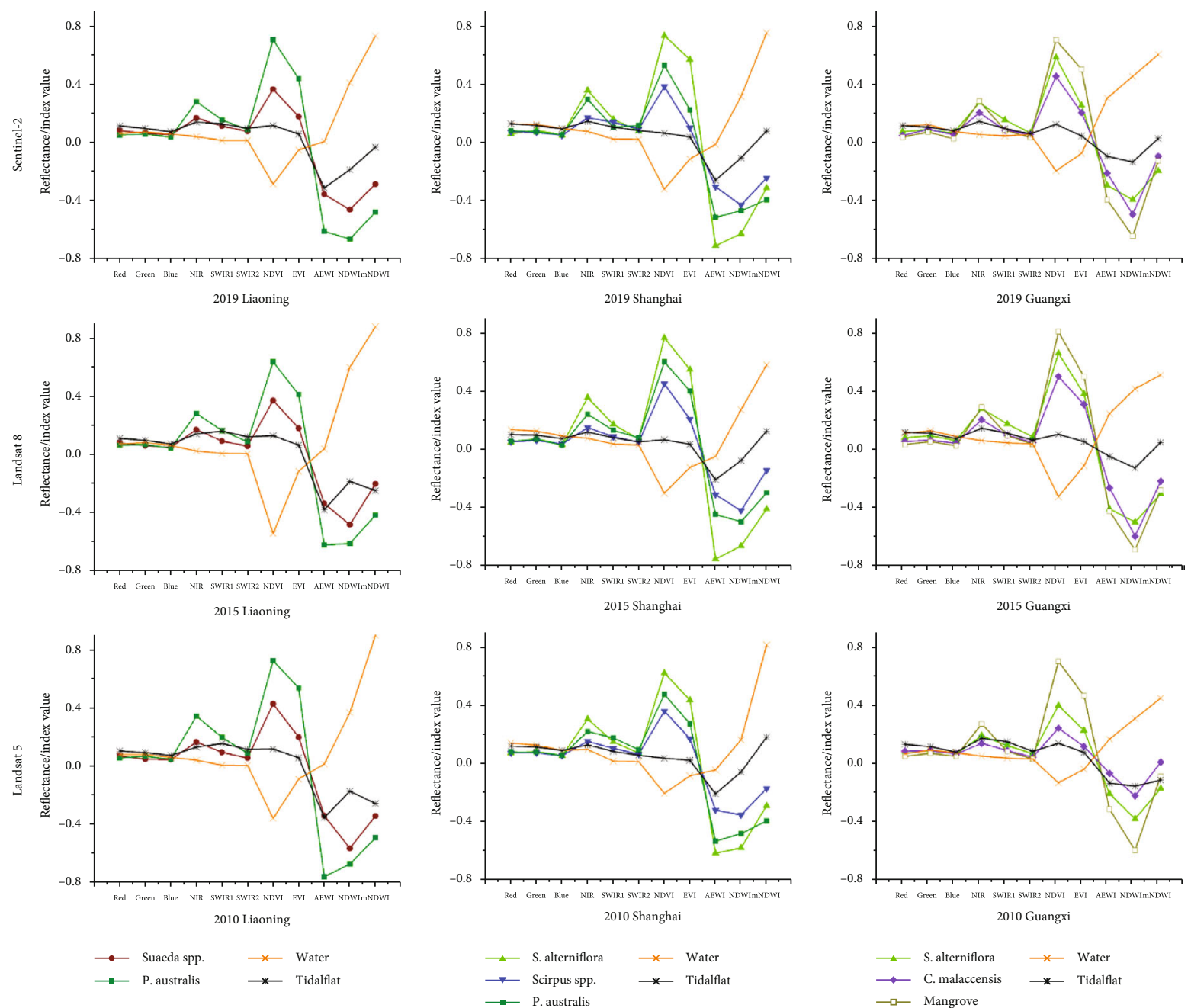

Figure 1: Spectral reflectance/index values for various salt marsh species in the different regions from Landsat 5/8 and Sentinel-2 images (as NIR, SWIR1, NDVI, EVI, AEWI, NDWI, and mNDVI have large differences among different regions and salt marsh species, they are used in SVM classification model).

Nominalized Difference Vegetation Index (NDVI) [35], Enhanced Vegetation Index (EVI) [36, 37], Normalized Difference Water Index (NDWI) [38], Modified Normalized Difference Water Index (mNDWI) [39], and Automated Water Extraction Index (AWEI) [40]. AWEInsh is an index formulated to effectively eliminate nonwater pixels and AWEIsh for further improvement of accuracy by removing shadow pixels that AWEInsh may not effectively eliminate. NDVI and EVI are related to vegetation greenness, and NDWI, mNDWI, and AWEI are sensitive to open surface water body. These indices have been used to identify vegetation [37, 41-43] and open surface water body [39, 44-46]. In addition, near infrared (NIR) band, short-wave infrared 1 (SWIR1) band, and short-wave infrared 2 (SWIR2) band were also applied to better identify salt marsh species. These quantities were calculated as follows:

$$
\mathrm{NDVI}=\frac{\rho_{\mathrm{NIR}}-\rho_{\mathrm{red}}}{\rho_{\mathrm{NIR}}+\rho_{\mathrm{red}}}
$$

$$
\begin{gathered}
\mathrm{EVI}=2.5 \times \frac{\rho_{\mathrm{NIR}}-\rho_{\text {red }}}{\rho_{\mathrm{NIR}}+6 \times \rho_{\text {red }}-7.5 \times \rho_{\text {blue }}+1}, \\
\mathrm{NDWI}=\frac{\rho_{\text {green }}-\rho_{\mathrm{NIR}}}{\rho_{\text {green }}+\rho_{\mathrm{NIR}}}, \\
\mathrm{mNDWI}=\frac{\rho_{\text {green }}-\rho_{\text {SWIR }}}{\rho_{\text {green }}+\rho_{\text {SWIR }}},
\end{gathered}
$$

$$
\text { AEWInsh }=4 \times\left(\rho_{\text {green }}-\rho_{\text {SWIR }}\right)-\left(0.25 \times \rho_{\text {NIR }}+2.75 \times \rho_{\text {SWIR } 2}\right),
$$

$\mathrm{AEWIsh}=\rho_{\text {blue }}+2.5 \times \rho_{\text {green }}-1.5 \times\left(\rho_{\text {NIR }}-\rho_{\text {SWIR } 2}\right)-0.25 \times \rho_{\text {SWIR2 }}$,

where $\rho_{\text {blue }}, \rho_{\text {green }}, \rho_{\text {red }}, \rho_{\text {NIR }}, \rho_{\text {SWIR }}$, and $\rho_{\text {SWIR } 2}$ are blue $(450-520 \mathrm{~nm})$, green $(520-600 \mathrm{~nm})$, red $(630-690 \mathrm{~nm})$, NIR (760-900 nm), SWIR1 (1550-1750 nm), and SWIR2 (2090$2350 \mathrm{~nm}$ ) bands of Landsat TM/OLI and Sentinel-2 images, 


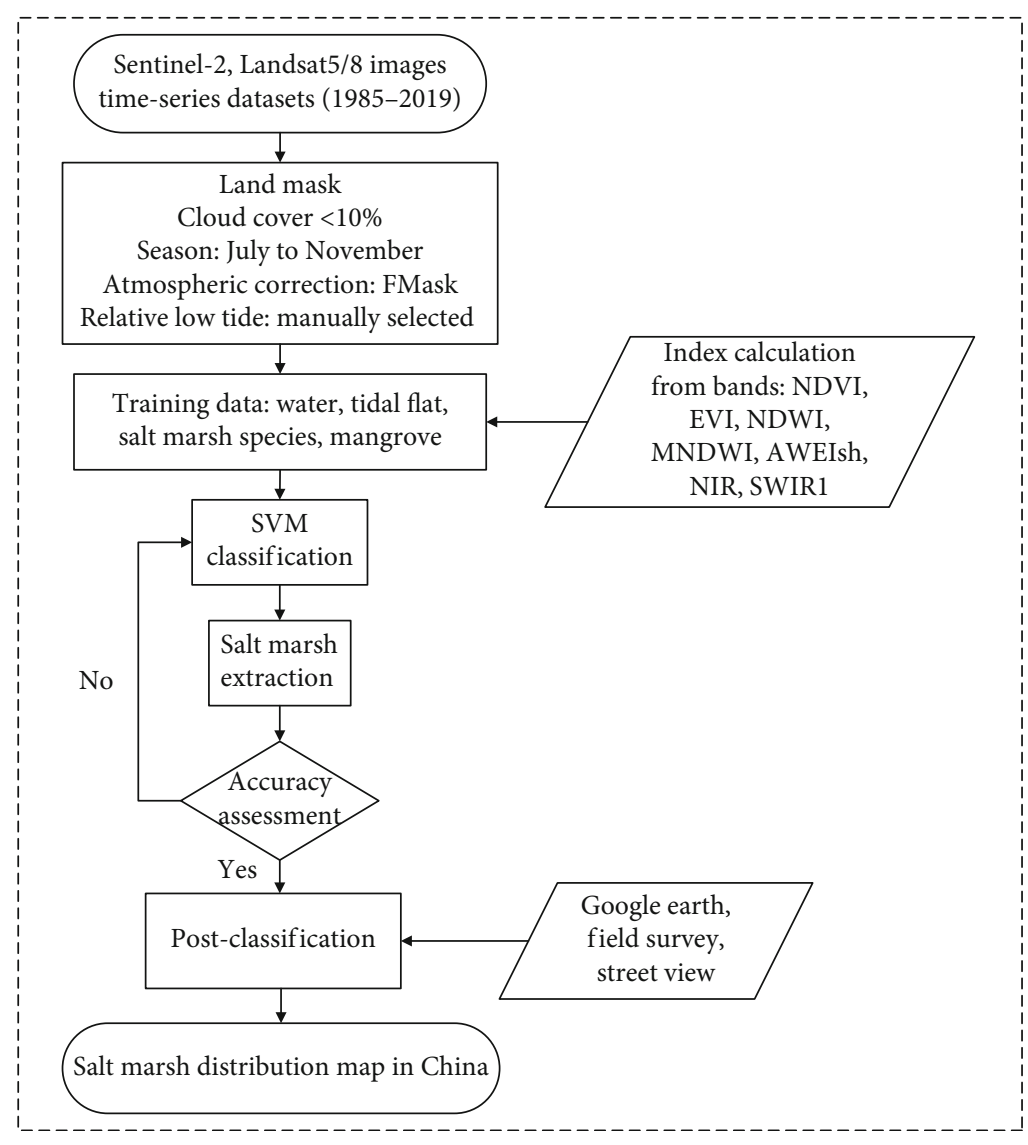

Figure 2: The flow chart of salt marsh classification.

respectively. Notice that the subscript "nsh" in Eq. (5) indicates that the index is suited for situations where shadows are not a major problem. The subscript "sh" in Eq. (6) indicates that the equation is intended to effectively eliminate shadow pixels and improve water extraction accuracy in areas with shadow and/or other dark surfaces [40].

Field survey and photos/videos taken by UAV helped improve the classification and corrected some misclassifications. For certain regions, such as Hainan, Macao, Hong Kong, and Taiwan, salt marsh distributions were too limited to be effectively identified and extracted from Landsat and Sentinel-2 images. Therefore, high-resolution images from Google Earth were used to visually interpret and manually extract salt marsh information based on knowledge and experience. Due to the limited number of studies concerned with salt marshes in Hong Kong, Macau, and Taiwan, we also used Google Street View to assist the identification of salt marsh species in small areas. The flow chart of salt marsh classification is shown in Figure 2.

2.4. Onsite Checking, Investigation, and Verification. In October 2019 and from August to November 2020, we carried out onsite checking, investigation, and verification, equipped with hand-held Global Positioning System (GPS), digital camera, and UAV. We recorded and studied the field salt marsh conditions in Liaoning, Shandong, Jiangsu, Shanghai, Zhejiang, Fujian, Guangdong, Guangxi, and Hainan (Figure 3, Tables S3). The UAV was used to examine the plant patches inaccessible to us. The aerial photos (R, G, B) were acquired by a Hasselblad L1D-20c of Dji Mavic-2 pro and a multispectral camera array with 5 cameras covering blue, green, red, red-edge, and near-infrared bands of Dji P4 Multispectral. The sampling and identification of salt marsh species were also conducted during the onsite survey.

\section{Results}

3.1. Classification Accuracy. We surveyed 52 locations to collect in situ salt marsh information. The accuracy of salt marsh classification results was evaluated based on the field survey data in 2019 and 2020. Among all samples, 70\% were selected as training data, and 30\% were used for validation purposes. The verification sample database is built based on field survey recorded data, UAV aerial photos, and Google Earth images. The commission error ranged from 0.07 to 0.11 , and validation accuracy ranged from 0.89 to 0.93 with a Kappa index between 0.86 and 0.91 (Table 1). Our classification had an accuracy greater than $85 \%$. In the salt marsh classification, the error sources were mainly the result of misclassification in the transitional zone. Due to the coarse resolution of Landsat images and the usually mixed distribution of multiple species of salt marshes, the area of $T$. chinensix is merged with the area of $P$. australis in Shandong, Scirpus spp. is grouped into Suaeda spp. in Jiangsu, P. australis is included in Scirpus spp. in Fujian, C. malaccensis is 


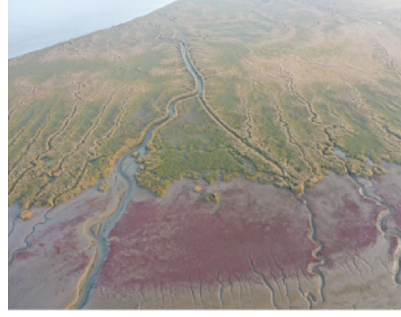

Panjin, Liaoning Oct. 22, 2019

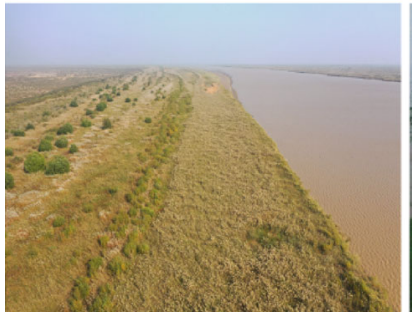

Dongying, Shandong Oct. 27, 2019

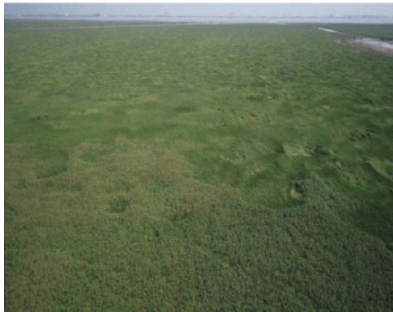

Chongming, Shanghai Sep. 5, 2020

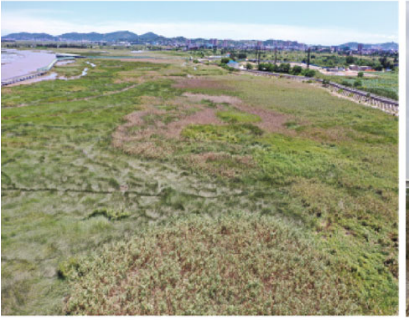

Fuzhou, Fujian Aug. 23, 2020

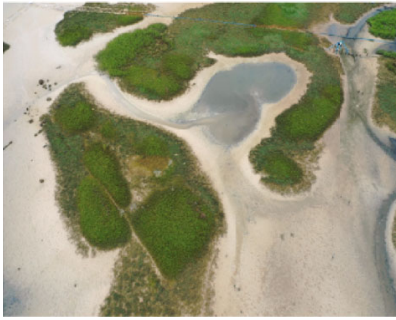

Wenchang, Hainan Aug. 26, 2020

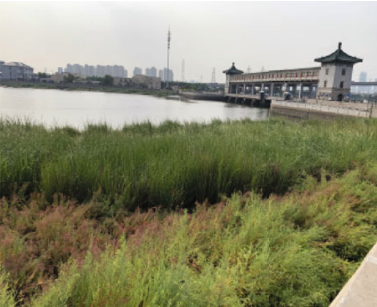

Binhai New District, Tianjin Sep. 24, 2020

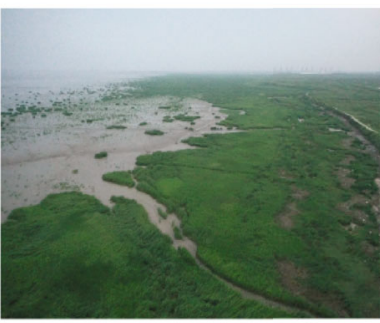

Yancheng, Jiangsu Sep. 2, 2020

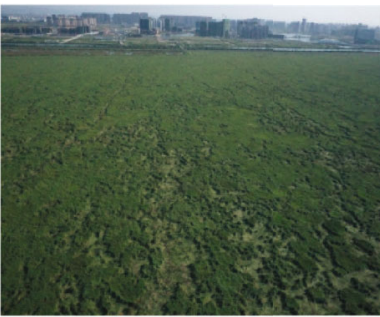

Cixi, Zhejiang Sep. 5, 2020

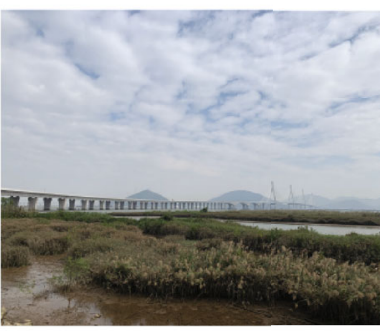

Zhuhai, Guangdong Nov. 8, 2020

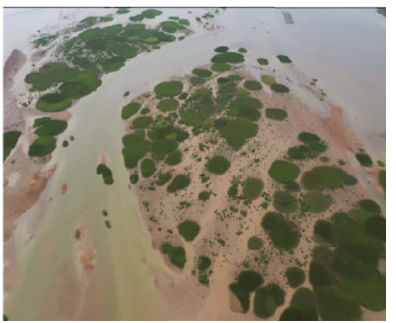

Beihai, Guangxi Aug. 30, 2020

Figure 3: Some examples of photos taken from field survey, showing salt marshes in various places.

merged with S. portulacastrum in Taiwan, and P. australis is combined with C. malaccensis in Guangxi, respectively.

$\mathrm{UAV}$ is used as a powerful tool of onsite investigation. In order to show the accuracy of classification results in a more objective manner, we selected Liaoning, Jiangsu, Fujian, and Guangxi as examples (see Figure 4, with red circles representing the points of UAV aerial shot), and subsequently compared the classification results with the field survey

TABLE 1: Overall accuracy (OA) and Kappa index of classification from 1985 to 2019.

\begin{tabular}{lccc}
\hline Year & Validation points & Validation OA & Validation kappa \\
\hline 2019 & 2723 & 0.93 & 0.91 \\
2015 & 2768 & 0.91 & 0.88 \\
2010 & 2471 & 0.90 & 0.86 \\
2005 & 2394 & 0.92 & 0.90 \\
2000 & 2285 & 0.90 & 0.87 \\
1995 & 2228 & 0.91 & 0.88 \\
1990 & 2100 & 0.89 & 0.87 \\
1985 & 2038 & 0.93 & 0.90 \\
\hline
\end{tabular}

and UAV aerial photos, thus proving that the obtained classification results of salt marsh vegetation were satisfactory.

3.2. Spatiotemporal Distribution of Salt Marshes. The areal extents of salt marsh vegetation in the intertidal zone of different coastal regions during 1985-2019 are summarized in Table 2 and Figure S1.

In general, the areal extents of intertidal salt marshes were varied substantially from 151,324 ha in 1985 to 115,397 ha in 2019 , with a net loss of 35,927 ha, accounting for $23.7 \%$ of national total. However, the areal variation is rather complex. The total area of salt marshes changed little and tended to be relatively stable from 1985 to 1995 . The area decreased sharply from 151,809 ha in 1995 to 87,639 ha in 2005 , resulting in 64,170 ha loss of salt marshes, about $42.3 \%$ of national total. Then, the area of salt marshes turned back from 2005 to 2015 . Thereafter, the area showed a clear recovery from 97,173 ha in 2010 to 115,397 ha in 2019 with an increase of 18,224 ha, about $18.7 \%$ more area in 2019 than that in 2010.

With regards to individual species of salt marshes, their changes differed greatly. The areal extent of $S$. alterniflora has been on the rise since 1985, with an average annual increase of 3,790 ha. After 2000, it has become the dominant species with a total of 67,527 ha in 2019 , accounting for $58.6 \%$ of national total marshes. S. alterniflora has been spread in all the coastal provinces of China in 2019. In Hainan, it was distributed in a very limited local area with sizes about $2-3 \mathrm{~m}^{2}$, which was hard to be reflected in Sentinel-2 image. The area of $P$. australis decreased continuously from 1985 to 2005 , reaching the lowest point $(27,521$ ha) in 2005 , and thereafter recovered slightly with a total of 33,193 ha in 2019. The area of Suaeda spp. increased marginally from 77,741 ha in 1985 to 85,216 ha in 1990 and then decreased dramatically, resulting in only 3,563 ha in 2019 . The area extent of Scirpus spp. reached its highest level $(13,869$ ha) in 2000, decreased slightly from 2000 to 2005, and then increased slowly with a total of 10,621 ha in 2019 . The area of S. portulacastrum was about 80 ha during 2005-2019 (Figure 5).

There were striking areal interchanges among the species of salt marshes, especially for S. alterniflora, Suaeda spp., and P. australis. The areal extents of both Suaeda spp. and $P$. australis have been generally kept dropping (from 


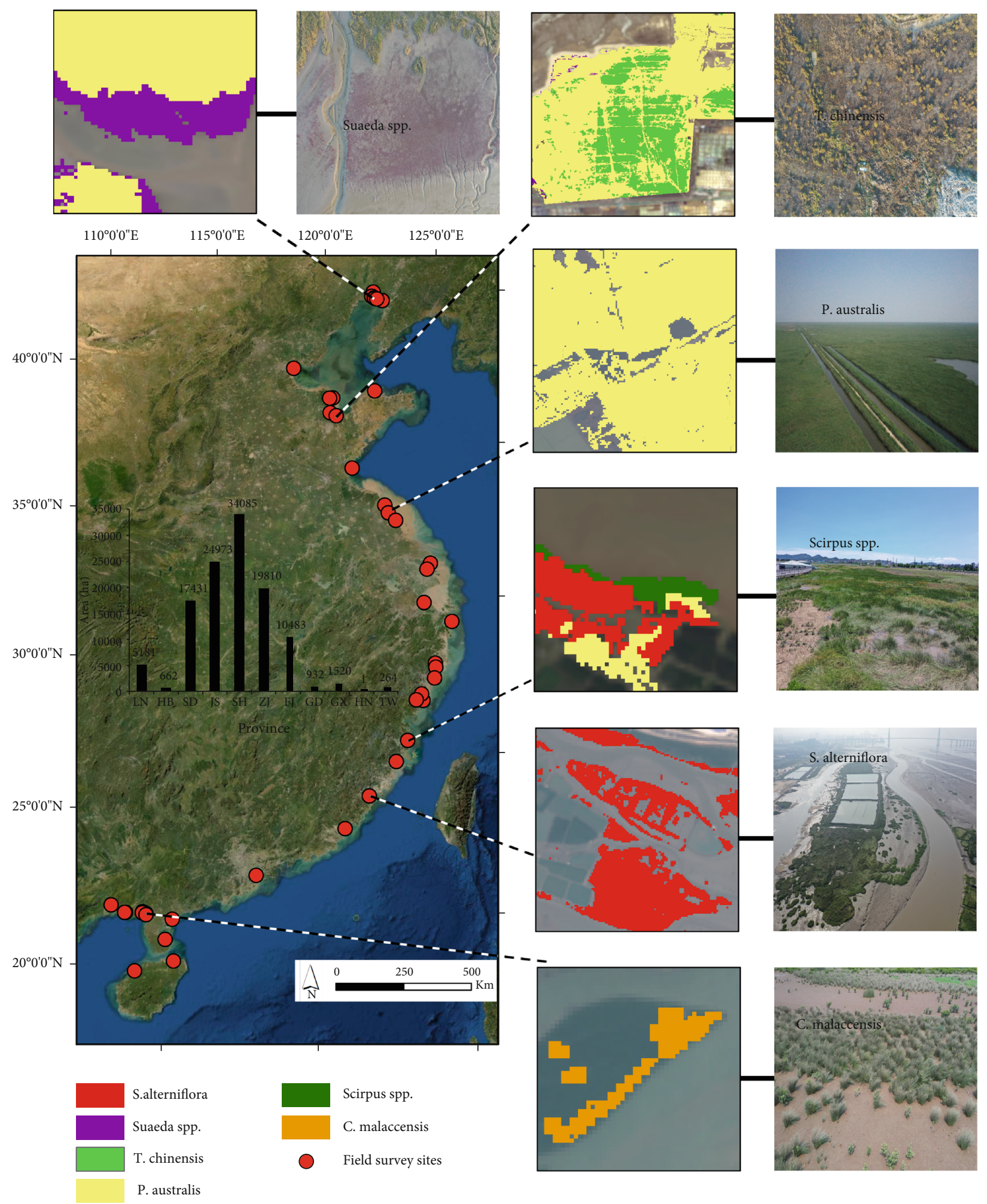

FIgURE 4: Geographical locations of field survey sites and typical salt marsh classification verification with aerial photo by UAV (subfigures clockwise from top left are Suaeda spp. in Liao River Delta, Liaoning, T. chinensis in the Yellow River Delta, Shandong, P. australis in Yancheng Nature Reverse, Jiangsu, Scirpus spp. in Minjiang River Estuary, Fujian, S. alterniflora in Jiulong River Estuary, Fujian, and C. malaccensis in Nanliu River Estuary, Guangxi in 2019). 
TABLe 2: Salt marsh species and areal extents (ha) in the intertidal zone of China during 1985-2019.

\begin{tabular}{|c|c|c|c|c|c|c|c|c|c|}
\hline Regions & Species & 1985 & 1990 & 1995 & 2000 & 2005 & 2010 & 2015 & 2019 \\
\hline \multirow{3}{*}{ Liaoning } & S. alterniflora & - & - & - & - & - & - & - & 33 \\
\hline & P. australis & 7924 & 6952 & 7006 & 5955 & 4921 & 4806 & 3497 & 3717 \\
\hline & Suaeda spp. & 5032 & 3159 & 3756 & 2795 & 2926 & 1982 & 2170 & 1431 \\
\hline \multirow{3}{*}{ Hebei and Tianjin } & S. alterniflora & - & - & 1.6 & 26 & 101 & 286 & 611 & 430 \\
\hline & P. australis & 752 & 480 & 397 & 192 & 70 & 130 & 94 & 204 \\
\hline & Suaeda spp. & 1827 & 708 & 967 & 484 & 0.4 & 15 & 13 & 27 \\
\hline \multirow{3}{*}{ Shandong } & S. alterniflora & - & - & - & - & - & 416 & 2920 & 6981 \\
\hline & P. australis ${ }^{\mathrm{a}}$ & 36111 & 16184 & 11102 & 11446 & 11519 & 10996 & 6063 & 8108 \\
\hline & Suaeda spp. & 33668 & 55570 & 49878 & 22315 & 9097 & 9492 & 3840 & 1591 \\
\hline \multirow{3}{*}{ Jiangsu } & S. alterniflora & 29 & 748 & 8389 & 18052 & 13658 & 14847 & 13766 & 16919 \\
\hline & P. australis & 6163 & 23270 & 20695 & 9967 & 4377 & 5191 & 8137 & 7593 \\
\hline & Suaeda spp. ${ }^{\mathrm{b}}$ & 37214 & 23830 & 23136 & 7632 & 9013 & 6649 & 802 & 461 \\
\hline \multirow{3}{*}{ Shanghai } & S. alterniflora & - & - & - & 77 & 4194 & 4878 & 9527 & 16228 \\
\hline & P. australis & 9104 & 9789 & 10943 & 10358 & 6139 & 9382 & 10107 & 11372 \\
\hline & Scirpus spp. & 8415 & 7416 & 7436 & 6407 & 4643 & 4860 & 4685 & 6486 \\
\hline \multirow{3}{*}{ Zhejiang } & S. alterniflora & 36 & 279 & 4136 & 8121 & 8327 & 11518 & 9364 & 14877 \\
\hline & P. australis & 413 & 712 & 1141 & 928 & 1334 & 1248 & 415 & 1063 \\
\hline & Scirpus spp. & 3131 & 4665 & 3022 & 7462 & 1929 & 2158 & 2313 & 3869 \\
\hline \multirow{2}{*}{ Fujian } & S. alterniflora & 2 & 2142 & 4135 & 4822 & 6246 & 6501 & 10574 & 10217 \\
\hline & Scirpus spp. ${ }^{c}$ & 284 & 169 & 259 & 182 & 27 & 34 & 132 & 266 \\
\hline \multirow{3}{*}{ Taiwan } & S. alterniflora & - & - & - & - & 12 & 112 & 98 & 149 \\
\hline & P. australis & - & - & - & - & 34 & 35 & 31 & 28 \\
\hline & S. portulacastrum ${ }^{\mathrm{d}}$ & - & - & - & - & 85 & 82 & 79 & 87 \\
\hline \multirow{2}{*}{ Guangdong $^{f}$} & S. alterniflora & 32 & 318 & 394 & 416 & 391 & 409 & 602 & 557 \\
\hline & C. malaccensis & 43 & 40 & 134 & 198 & 218 & 173 & 230 & 356 \\
\hline \multirow{2}{*}{ Guangxi } & S. alterniflora & - & - & - & 26 & 147 & 372 & 1114 & 1133 \\
\hline & C. malaccensis $^{\mathrm{e}}$ & 1143 & 864 & 903 & 644 & 266 & 154 & 224 & 387 \\
\hline Hainan & P. australis & - & - & - & - & - & - & 1 & 1 \\
\hline Total & & 151324 & 157776 & 151809 & 117599 & 87639 & 97173 & 91411 & 115397 \\
\hline
\end{tabular}

Note: ${ }^{a}$ mixed occurrence of P. australis and T. chinensix; ${ }^{\mathrm{b}}$ mixed Suaeda spp. and Scirpus spp.; ${ }^{\mathrm{c}}$ mixed Scirpus spp. and P. australis; ${ }^{\mathrm{d}}$ mixed S. portulacastrum and C. malaccensis; ${ }^{\mathrm{e}}$ mixed C. malaccensis and P. australis; ${ }^{\mathrm{f}}$ including the area of salt marshes in Hong Kong and Macau.

77,741 to 3,563 ha for Suaeda spp. and from 60,511 to 33,193 ha for $P$. australis), while that of S. alterniflora has been on the rise (from 99 to 67,527 ha) during the study period of 35 years. In 1985, Suaeda spp. had the largest area while S. alterniflora was 99 ha only. In 2019, the area of Suaeda spp. dropped its lowest but S. alterniflora reached its highest. In terms of their areal extents, the lost area of Suaeda spp. (74,178 ha) was about $90.9 \%$ compensated by the increased area $(67,428 \mathrm{ha})$ of $S$. alterniflora during the study period.

With the view of temporal domain, from 1990 to 1995 , the area of Suaeda spp., P. australis, and Scirpus spp. all showed a shrinking trend, while S. alterniflora and C. malaccensis increased by 10,832 ha and 39 ha, respectively. From 1995 to 2000, the area of Suaeda spp. decreased sharply, with an annual loss of 8,314ha. S. alterniflora and Scirpus spp. showed a gradual increasing trend. However, from 2000 to
2005, the total area of S. alterniflora showed strong rising, while P. australis, Scirpus spp., Suaeda spp., and C. malaccensis were all shrinking. The areal changes of these kinds of salt marshes had slowed down from 2005 to 2010. In 2005, S. alterniflora became the most abundant, $P$. australis the second, and S. portulacastrum the least. From 2015 to 2019, S. alterniflora, P. australis, and Scirpus spp. all showed a rising trend, while the area of Suaeda spp. decreased.

\section{Discussion}

4.1. Reliability and Uncertainty of Salt Marsh Classification Using Landsat Series and Sentinel Data. We delineated a total of 115,397 ha salt marshes in 2019 in China, which provides a baseline with different salt marsh species to assess subsequent changes. Due to the spatial resolution of images ( $30 \mathrm{~m} \times 30 \mathrm{~m}$ from 1985 to 2015 and $10 \mathrm{~m} \times 10 \mathrm{~m}$ in 2019), 


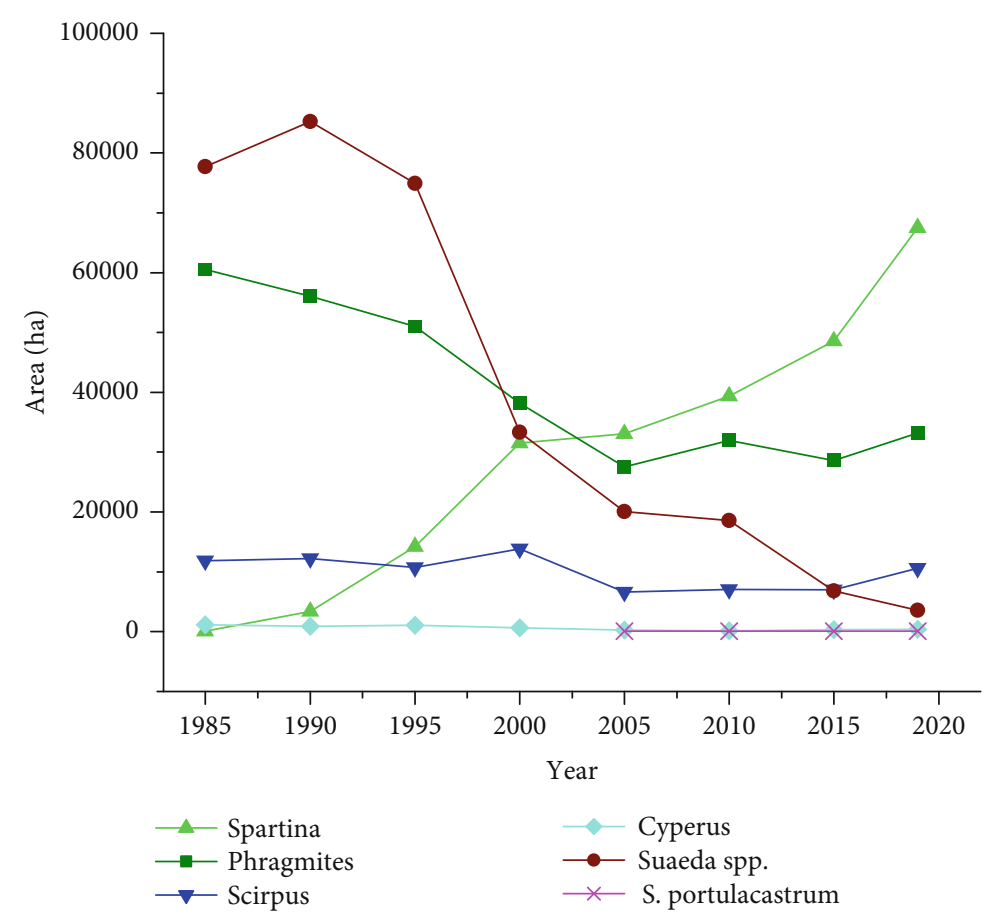

FIgURE 5: Temporal variation of areal extents among the mapped salt marshes.

some small patches of salt marshes could not be identified; thus, we would consider the total extent of salt marshes reported here as a conservative one.

$\mathrm{Hu}$ et al. [12] mapped coastal salt marshes in China using time series of Sentinel-1 SAR data and reported 127,477 ha with 4 species of salt marshes. Our results were $7.5 \%$ lower than that of $\mathrm{Hu}$ et al. [12], which could be mainly attributable to the discrepancy of the study areas. By contrasting the coastline information from Open Street Map, and making interpretation on remote sensing images, we manually adjusted and updated both the natural and manmade coastline across the entire coast. In this way, we obtained the coastline. With this coastline as the basis, we extended 10 kilometers towards the seaside as the study area. $\mathrm{Hu}$ et al. [12] mainly used natural coastline to delineate the potential areas. In theory, $\mathrm{Hu}$ et al. [12]'s study area is larger than ours. In addition, our approach used multispectral information from visible to infrared and indices, while $\mathrm{Hu}$ et al. [12] used SAR information. This would lead to the difference in distinguishing ground objects. We found that $\mathrm{Hu}$ et al. [12] mapped P. australis in Yueqing Bay, Zhejiang Province where our result showed S. alterniflora covered the area. In southern China, $P$. australis usually grows mixed with C. malaccensis, and the latter is dominant in Guangxi. $\mathrm{Hu}$ et al. [12] did not report C. malaccensis but only $P$. australis in this region. In some cases, such as Suaeda spp., newly transplanted or growing salt marshes, could be quite short and small and sparsely distributed, showing low reflectance in multispectral imagery. Sometimes, they could be difficult to be differentiated from tidal flats. In sum, there are certainly some advantages and disadvantages of both approaches. Therefore, the integration of SAR and multispectral information could be one way to improve the work.
Liu et al. [28] mapped a total of 54,480 ha S. alterniflora in China using Landsat 8 data, which was about 10.8\% higher than our data. With the same as $\mathrm{Hu}$ et al. [12], Liu et al. [28] studied only the mainland coastal zone, and the study area was larger than ours.

In this study, the quality and the inconsistent availability of images at temporal and spatial scales, along with our algorithms, could have introduced some uncertainties in our result. As we only have some photos taken from field survey during 2019-2020, and lack of field survey data in other years, this will have certain impacts on the assessment of our classification results. In the future, other sensors (e.g., GF-7, Worldview-4) with higher spatial and temporal resolution become available, which will further help improve coastal wetland mapping.

4.2. Driving Factors for Spatiotemporal Dynamics of Salt Marshes in the Coastal Zone. As one of the Blue carbon ecosystems, salt marshes are of great ecoenvironmental value and also have strong carbon sequestration capacity, which plays an important role in climate change mitigation/adaptation. However, dramatic changes have taken place in this ecosystem. For example, Yang and Chen [47] reported that about 708,200 ha of wetlands had been reclaimed from 1949 to 1994 , which was six times more than the current area of salt marshes. Our results showed that there was a further reduction of 36,412 ha salt marshes from 1995 to 2019. Many potential factors affect the distribution of salt marshes, including coastal reclamation, anthropogenic intervention, runoff and sediment transport, climate change, species competition, and sea level change [5, 28, 30, 48-50]. These factors influence and interact with each other. This paper discusses on the impact of coastal reclamation, anthropogenic 


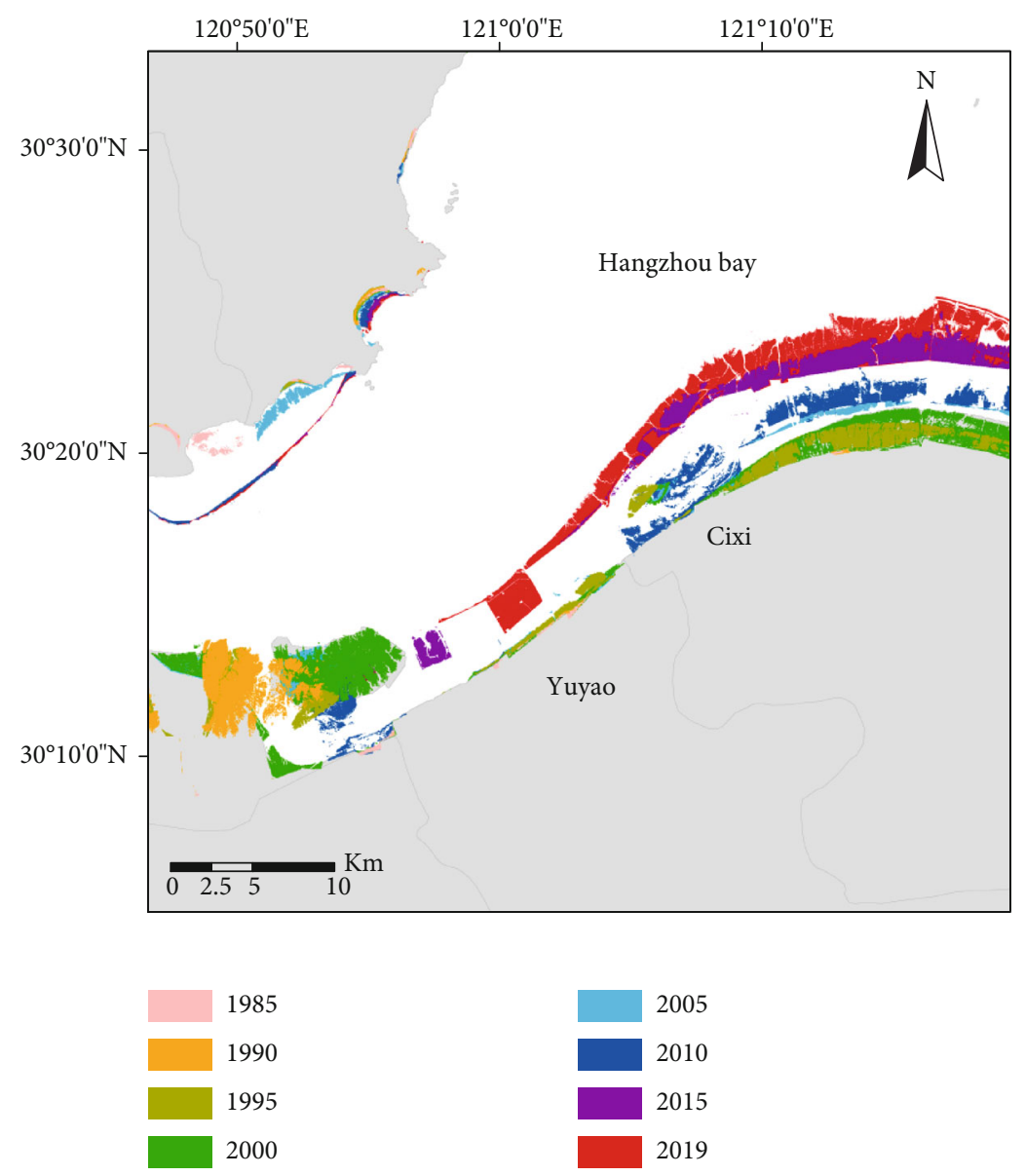

Figure 6: Salt marsh distribution in Hangzhou Bay from 1985 to 2019 (the different color indicates the year when the salt marshes were appeared for the first time).

intervention, runoff and sediment transport, climate change, and species competition on salt marshes.

Anthropogenic activities, especially coastal reclamation, were identified as the major driving factor influencing salt marshes in China $[5,30]$. These activities, directly or indirectly, affect the existence/occurrence or distribution of salt marshes. Like in the Liao River Delta, Tianjin coast, the Yellow River Delta, Jiangsu coast, the Yangtze River Delta, and the Hangzhou Bay regions, anthropogenic intervention and infrastructure mainly took the place of salt marshes. During the period 1985 to 2010, the reclamation area of coastal wetlands in mainland China was 755,186 ha [51]. Shoreline changes caused by reclamation had a great influence on the distribution of salt marshes, of which a typical case was in the southern Hangzhou Bay (Figure 6). In general, the temporal reduction of salt marshes has similar trend with reclamation areas in the southern Hangzhou Bay, which indicating that salt marshes loss is closely related to reclamation activities. We used the spatial overlay analysis method to analyze the reclamation area and reduction area of salt marshes in southern Hangzhou Bay during 1995-2015 (Figure 7). From 1985 to 1990, the area of salt marshes along the Yuyao coast was relatively small. The area of salt marshes expanded significantly from 1990 to 2000. During 2000-2005, the reclamation area of the southern Hangzhou
Bay was 12,615 ha, resulting in a sharp decrease of salt marshes. The reduced salt marsh area accounted for $23.0 \%$ of the total area in Zhejiang in the period. From 2005 to 2010, reclamation area on the southern Hangzhou Bay continued to increase by 10,460 ha. As a result, the area of salt marshes decreased by 1,677 ha. Due to the consistent reclamation, salt marshes showed seaward movement along with the change of coastline. By 2010, the salt marsh area had increased due to the quick expansion of S. alterniflora. In $2015,32.0 \%$ of salt marshes were turned into ponds for fishery, the reclamation area continued to increase by 18,552 ha, and the coastline continued to move seaward (Figure 7). Ye et al. [52] reported that shoreline changing had been the most intense from 2000 to 2005, and the annual reduction of shoreline length was $9.87 \mathrm{~km}$ on average. This study found that the salt marsh area in Zhejiang decreased significantly from 2000 to 2005 with an annual loss of 704 ha, indicating that anthropogenic exploitation had a great influence on salt marsh distribution.

Anthropogenic intervention in salt marsh species also has great effects on their distribution. S. alterniflora was initially introduced from North America into Jiangsu in late 1970's for the purpose of sediment accretion. In the early 1990s, Shanghai also introduced S. alterniflora to increase sedimentation and land formation. Since then, S. alterniflora 


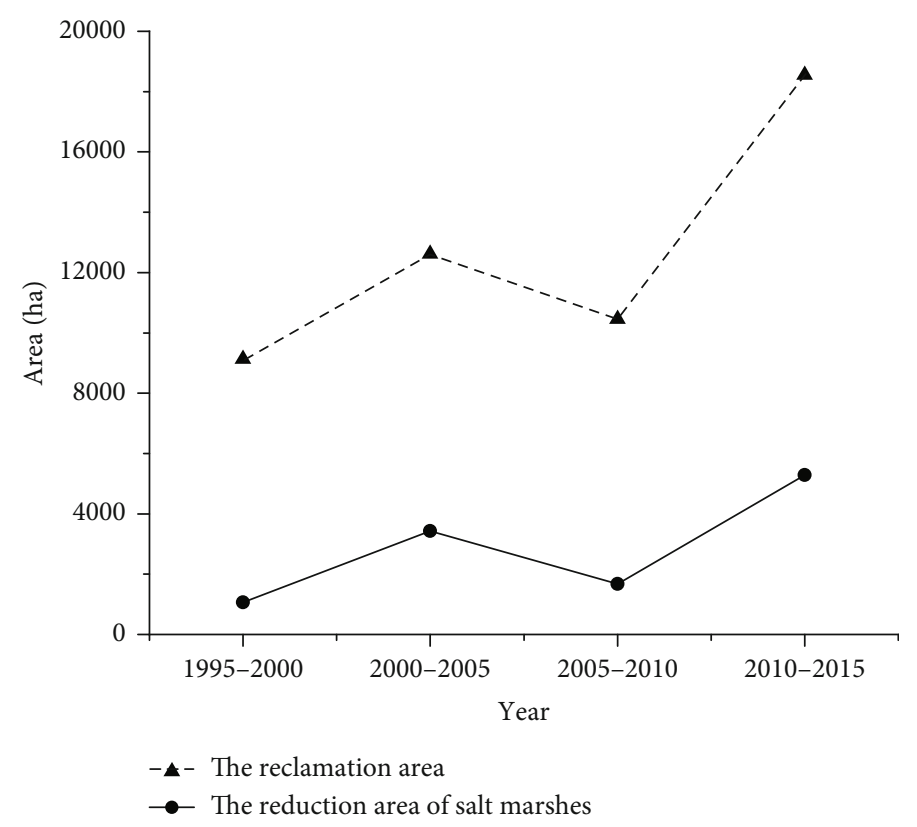

FIgURE 7: The reclamation area and reduction area of salt marshes in the southern Hangzhou Bay during 1995-2015.

has spread further in other regions and even invaded the native salt marsh communities [53]. A comprehensive control project on S. alterniflora was carried out in Chongming Island in 2012. A large area of S. alterniflora was cut, and $P$. australis was planted in 2013, leading to a shift of salt marsh species composition. Similarly, the main purpose of $S$. alterniflora introduced in Shandong was to control pollution, promote sedimentation, and protect environment. The strong capability of $S$. alterniflora to promote sedimentation and land formation has provided a large area of tidal flats in Haiyang City and Yantai City, which has been turned into shrimp ponds [46]. Anthropogenic activities, such as shipping, fishing, and tourism, can also increase the possibility of seed dispersal in salt marshes [54]. For example, in recent years, a large number of $S$. alterniflora were found in Tianjin Port and Weifang Port. S. alterniflora has spread from the very northern coast of Liaoning to the further south of Hainan. It is evident that, after being introduced, S. alterniflora has adapted to very different climatic and geographic conditions along the Chinese coast. Being an invasive plant with significant negative impact on local ecology, it is suggested that serious control measure on S. alterniflora should be taken nationwide. Lastly, environmental pollution from industrial production and oil exploration can also have an impact on salt marshes [55] \{Lin, 2009 \#91\}. The Liao River Delta and the Yellow River Delta are rich in petroleum resources. The industrial pollution produced in the process of petroleum exploitation and processing has resulted in great loss of local Suaeda spp. and P. australis.

Water is the key factor for the formation and sustainable existence of wetlands [56], while sediment is the material basis for the formation of intertidal salt marshes. Thus, the change of salt marsh area is closely associated with the runoff and sediment transport from seashore rivers. Based on the sediment discharge data at the Lijin Station [57] in the Yellow River Delta and at the Datong Station [58] in the Yangtze River Delta, we analyzed the effect of runoff and sediment transport changes on salt marsh growth. The annual runoff and sediment discharge of the Lijin Station showed a shrinking trend from 1983 to 1998, and the annual runoff increased slightly from 1998 to 2013, while the annual sediment discharge changed little. The annual sediment transport showed a general shrinking trend from 1983 to 2013, indicating that the sediment transport decreased year by year and the formation of new tidal flats also decreased (Figure 8). Lu et al. [59] reported that the overall runoff and sediment transport of the Yellow River showed a shrinking trend from 1973 to 2012, which had a good correlation with the shrink of delta wetland area, especially with the reduction of natural wetland.

The salt marshes in Shandong are mainly concentrated in the Yellow River Delta. The area of salt marshes in this region showed a quick shrinking trend from 1990 (71,754 ha) to 2015 (12,823 ha), and the interannual change rule of salt marshes was consistent with the annual change of sediment transport, which was in agreement with the previous study [57]. From 1985 to 2010, sediment transport from the Yellow River to the sea decreased sharply, and the lower reaches of the Yellow River were frequently cut off. The original wetland ecosystem was broken, and the delta wetland was in degradation, with $P$. australis being degraded to Suaeda spp. and Suaeda spp. being degraded to tidal flat. In 1996, the main channel of the Yellow River to the sea was blocked, and the Yellow River was forced to turn to the northeastern direction to enter the sea, resulting in a further degradation of salt marshes. In 2019, a new peninsula was formed at the junction of the Yellow River and Bohai Sea. Therefore, the distribution of salt marshes in 

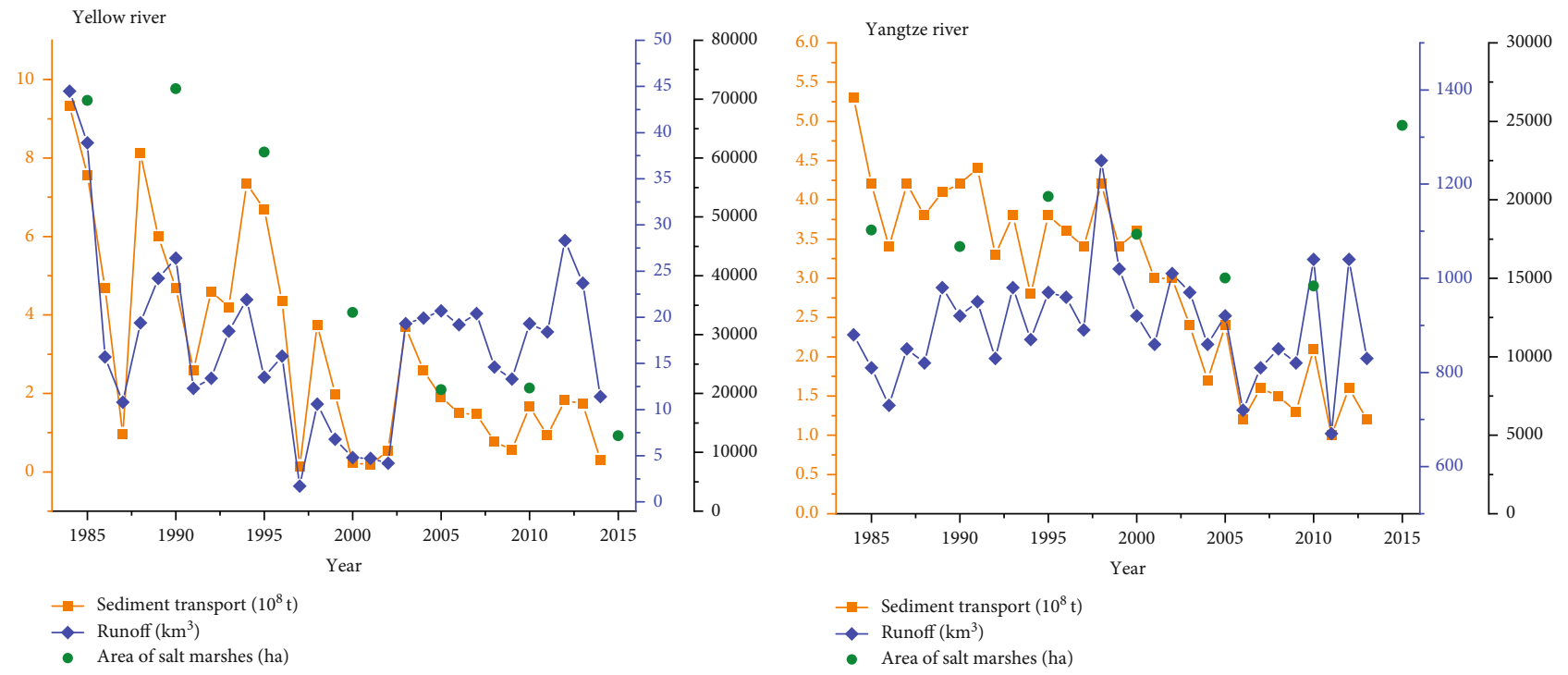

Figure 8: The annual variations of runoff, sediment transport, the area of salt marshes, and the delta front in the Yellow River Delta and Yangtze River Delta.

the Yellow River gradually shifted from southeast to northeast. Although the runoff of the Yellow River has increased after 2010, it was difficult to shift the degradation trend of regional salt marshes, due to the long-term water shortage in the earlier period of the year as well as the change of the Yellow River Estuary to the northeast (Figure 9).

Wei et al. [58] reported that the annual runoff at the Datong Station of the Yangtze River changed greatly from 1985 to 2010 . The annual sediment transport varied greatly from 1985 to 2001 and showed a linear downward trend after 2001. The area of salt marshes in Shanghai decreased from 18,379 ha in 1995 to 14,976 ha in 2005. Later, with the spread of $S$. alterniflora, the area of salt marshes in Jiuduansha Shoal increased continuously (Figure 8). It can be seen that river runoff and sediment transport are closely associated with the change of salt marsh area.

Climatic conditions further affect the growth and distribution of salt marshes. In recent years, due to the global warming and uneven interannual precipitation, the reduction of water flow in rivers in northern China has limited the growth of salt marshes [28]. The increase of temperature promoted evaporation of salt marsh wetlands, resulting in an increase of soil salinity, thus affecting the growth of plants with weak salt tolerance, such as $P$. australis. Meanwhile, sea-level rise leads to seawater intrusion, which also increases the frequency and time of seawater innudation on intertidal flats, leading to further increase of soil salinity and erosion [60]. Chen [61] found that Scirpus spp. grew well at $0 \% 0-4 \%$ salinity, and its growth was significantly inhibited at $16 \%$ salinity, while at $32 \%$ salinity, Scirpus spp. died completely. Wang [62] showed that there was a significant negative correlation between the performance of Scirpus spp., P. australis, and salinity, indicating that salinity had a significant inhibition effect on the growth of Scirpus spp. and $P$. australis. In addition, due to global warming, global sea level has continued to rise at an average annual rate of 1-3 mm during the past 100 years [60]. It is estimated that the region most affected by sea-level rise is in the Yangtze River Delta, which is facing the sea level rise at an annual rate of 6.5-11.0 mm [62], followed by the abandoned Yellow River Delta and the north of Hangzhou Bay. Spencer et al. [63] predict that if sea level rises by $500 \mathrm{~mm}$, the global coastal wetlands will decrease by $46 \%-59 \%$. Considering the fact that the elevation of most coastal areas in China is lower than $3 \mathrm{~m}$, severe sea level rise caused by melting of the Arctic and Antarctic glaciers would reduce the area of salt marshes. When sea-level rise exceeds the rate of sediment deposition, subtidal salt marshes will gradually degrade to unvegetated tidal flats. Meanwhile, dams built with cement along the coastline inhibit the landward migration of salt marshes, further leading to the loss of salt marshes. In contrast, sea-level rise may help invasive species to exert their competitive advantages and increase the impact of invasive species on salt marsh communities and the entire salt marsh ecosystem [64].

Salt marsh species compete for ecological niches in intertidal zones. S. alterniflora has been expanding along the coastal China due to its strong adaptability, competing with native species and eventually replacing its ecological niche to become the dominant species in the region. Wang [50] found that before $S$. alterniflora invasion, the spatial sequence and succession sequence of salt marsh vegetation along the elevation from low to high in the Yangtze River Estuary were as follows: tidal flats-Scirpus spp. community$P$. australis community. However, the invasion of S. alterniflora broke the pattern. In the tidal flats with high salinity, Scirpus spp. and other sedges may completely disappear, and the succession sequence was as followed: tidal flats- $S$. alterniflora community- $P$. australis community. In the low salinity tidal flats, the succession sequence was as follows: Scirpus spp. communit-S. alterniflora community-P. australis community, but the distribution range and area of Scirpus 


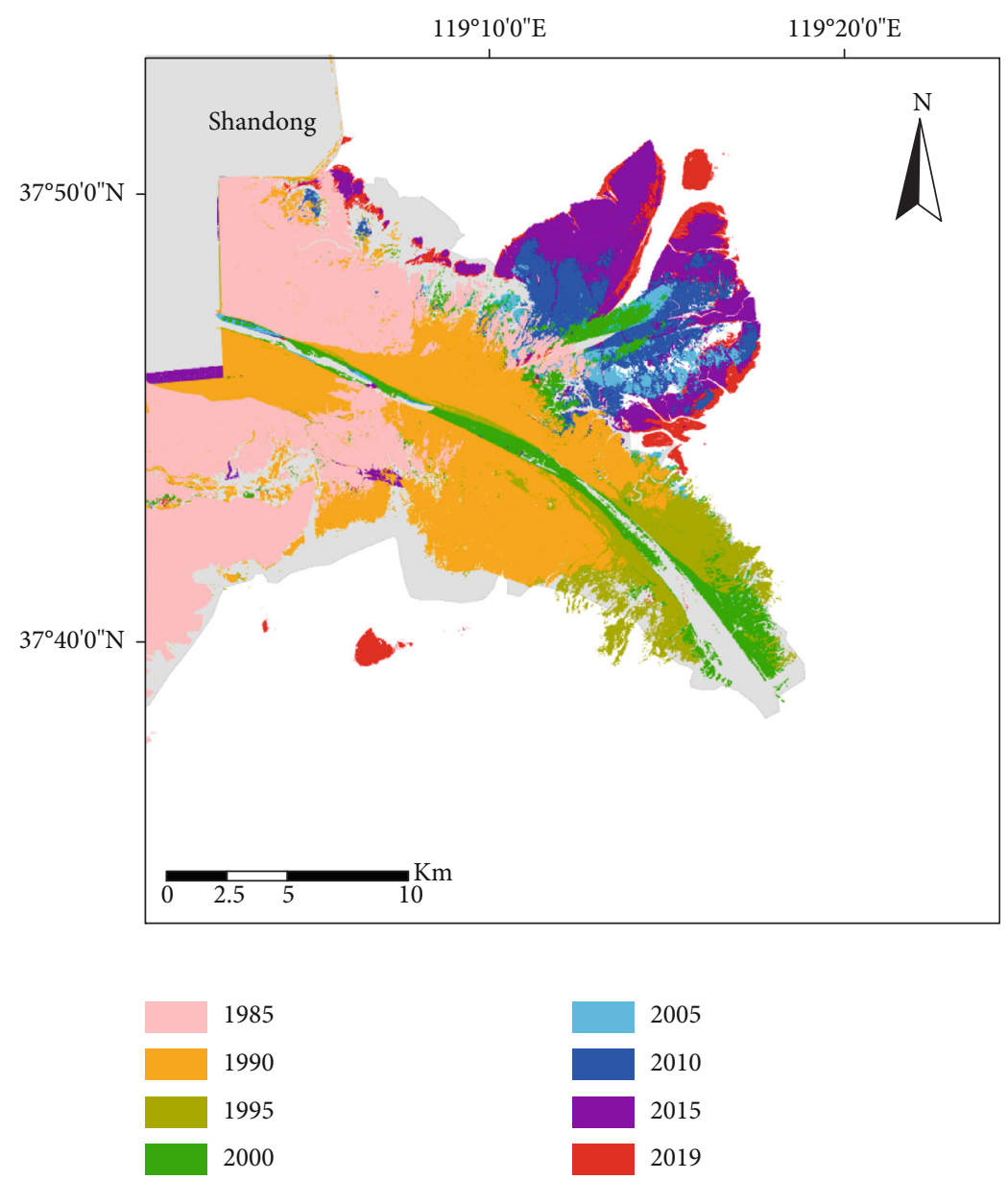

FIgURE 9: Distribution of salt marshes in the Yellow River Delta during 1985-2019.

spp. community and $P$. australis community still shrunk significantly. Similarly, in Yancheng (Jiangsu), the competition of salt marsh distribution pattern was from $P$. australisSuaeda spp. competition in 1985, to P. australis-Suaeda spp. competition and S. alterniflora-Suaeda spp. competition coexistence in 2000, to $P$. australis-S. alterniflor-Suaeda spp. community cocompetition in 2010, and finally to $P$. australis-S. alterniflora community competition in 2015.

In sum, coastal reclamation is the first and major driving force that causes the changes of intertidal salt marshes, while natural factors also exert their considerable influences. In the future, sea-level rise, environmental pollution, and coastal reclamation will further threaten salt marsh habitats, and invasive species will have a greater impact on local salt marshes if without any control. According to the analysis of these influencing factors, we should make corresponding strategies to mitigate negative effects on salt marsh distribution, strengthen the protection and management of salt marshes, and improve the ecoenvironmental function of wetlands.

\section{Summary}

This study used an approach based on satellite data to map salt marshes and assess their interannual variation in the intertidal zone of China during 1985-2019. The total area of salt marshes was 151,324 ha in 1985 and then reduced to 115,397 ha in 2019 , with a loss of $23.8 \%$. Seven major species of salt marshes were identified. They are mainly distributed in Liaoning, Shandong, Jiangsu, Shanghai, and Zhejiang and show various patterns and dynamics of shrinking or expansion in different places. During the study period, the areas of two major native species, Suaeda spp. and P. australis, have dropped greatly while that of $S$. alterniflora has exhibited a sharp rise. Changes in the areal extent and species compositions of salt marshes are the result of the combined influence of anthropogenic and natural factors. In the past 35 years, land reclamation has the greatest impact on the distribution of salt marshes. China is implementing ambitious saltmarsh conservation and restoration projects, i.e., strictly controlled land reclamation, and has strengthened the integrated coastal zone management and coastal wetland protection. The implementation of these measures alleviated the pressure and negative impact of land reclamation on the salt marsh wetland to a certain extent. Thus, the area of salt marshes may present an upward trend in the future. The results of the present study provide important referencing data for "Blue Carbon" program and will be helpful in the effort to achieve the goal of "Carbon Neutrality" in China. 


\section{Data Availability}

The data that support the findings of this study are available from the corresponding authors upon request.

\section{Conflicts of Interest}

The authors declare that there is no conflict of interest regarding the publication of this article.

\section{Authors' Contributions}

J.W., R.J., G.C., and J.G. conceived and designed the study. G.C. processed the data and drafted the manuscript. R.J., Z.Y., Q.L., J.W., and D.L. joined the research and fieldwork. All authors joined the research, reviewed the manuscript, and agreed to the submitted version of the manuscript. We are very grateful to the Editor and two anonymous reviewers for their thoughtful comments/suggestions, which have been used in revising this paper.

\section{Acknowledgments}

This study was supported in part by the Ministry of Natural Resources (Blue Carbon Initiative and Policy), the Department of Science and Technology, Zhejiang Province (2016C04004) and the Fundamental Research Funds for the Zhejiang Provincial Universities (2021XZZX012).

\section{Supplementary Materials}

Supplementary data associated with this article can be found, in the online version, at website. (Supplementary Materials)

\section{References}

[1] V. J. Chapman, "Salt marshes and salt deserts of the world," Journal of Ecology, vol. 79, no. 13, pp. 3-19, 1974.

[2] P. Zuo, S. Zhao, C. Liu, C. Wang, and Y. Liang, "Distribution of Spartina spp. along China's coast," Ecological Engineering, vol. 40, pp. 160-166, 2012.

[3] J. Wu, H. Zhang, Y. Pan et al., "Opportunities for blue carbon strategies in China," Ocean and Coastal Management, vol. 194, article 105241, 2020.

[4] Y. Zheng, R. Jin, X. Zhang, Q. Wang, and J. Wu, "The considerable environmental benefits of seaweed aquaculture in China," Stochastic Environmental Research and Risk Assessment, vol. 33, no. 4-6, pp. 1203-1221, 2019.

[5] J. Gu, M. Luo, X. Zhang et al., "Losses of salt marsh in China: trends, threats and management," Estuarine Coastal and Shelf Science, vol. 214, pp. 98-109, 2018.

[6] R. Zhang, Y. Shen, L. Lu et al., "Formation of Spartina alterniflora salt marshes on the coast of Jiangsu Province, China," Ecological Engineering, vol. 23, no. 2, pp. 95-105, 2004.

[7] R. L. Hinkle and W. J. Mitsch, "Salt marsh vegetation recovery at salt hay farm wetland restoration sites on Delaware Bay," Ecological Engineering, vol. 25, no. 3, pp. 240-251, 2005.

[8] X. Xiao, S. Agusti, F. Lin et al., "Nutrient removal from Chinese coastal waters by large-scale seaweed aquaculture," Scientific Reports, vol. 7, p. 1, 2017.
[9] C. M. Duarte, J. Wu, X. Xiao, A. Bruhn, and D. Krause-Jensen, "Can seaweed farming play a role in climate change mitigation and adaptation?," Frontiers in Marine Science, vol. 4, p. 100, 2017.

[10] Q. Yu, P. Gong, N. Clinton, G. Biging, M. Kelly, and D. Schirokauer, "Object-based detailed vegetation classification. With airborne high spatial resolution remote sensing imagery," Photogrammetric Engineering and Remote Sensing, vol. 72, no. 7, pp. 799-811, 2006.

[11] A. Wang, S. Gao, and J. Jia, "Impact of S. Alterniflora on sedimentary and mor-phological evolution of tidal salt marshes in Jiangsu, China," Acta Oceanologica Sinica, vol. 28, no. 1, pp. 92-99, 2006.

[12] Y. Hu, B. Tian, L. Yuan et al., "Mapping coastal salt marshes in China using time series of Sentinel-1 SAR," ISPRS Journal of Photogrammetry and Remote Sensing, vol. 173, pp. 122-134, 2021.

[13] J. Gu, R. Jin, G. Chen et al., “Areal extent, species composition, and spatial distribution of coastal saltmarshes in China," IEEE Journal of Selected Topics in Applied Earth Observations and Remote Sensing, vol. 14, pp. 7085-7094, 2021.

[14] W. He, R. Feagin, J. Lu, W. Liu, Q. Yan, and Z. Xie, "Impacts of introduced Spartina alterniflora along an elevation gradient at the Jiuduansha Shoals in the Yangtze Estuary, suburban Shanghai, China," Ecological Engineering, vol. 29, no. 3, pp. 245-248, 2007.

[15] H. Huang and L. Zhang, "A study of the population dynamics of Spartina alterniflora at Jiuduansha shoals, Shanghai, China," Ecological Engineering, vol. 29, no. 2, pp. 164-172, 2007.

[16] H. Li and L. Zhang, "An experimental study on physical controls of an exotic plant Spartina alterniflora in Shanghai, China," Ecological Engineering, vol. 32, no. 1, pp. 11-21, 2008.

[17] M. Thomas and A. Reid, "Are exotic natural enemies an effective way of controlling invasive plants?," Trends in Ecology \& Evolution, vol. 22, no. 9, pp. 447-453, 2007.

[18] D. R. Ayres, D. L. Smith, K. Zaremba, S. Klohr, and D. R. Strong, "Spread of exotic cordgrasses and hybrids (Spartina sp.) in the tidal marshes of San Francisco Bay, California, USA," Biological Invasions, vol. 6, no. 2, pp. 221-231, 2004.

[19] R. Huang, C. Zhang, X. Xu et al., "Underestimated PAH accumulation potential of blue carbon vegetation: Evidence from sedimentary records of saltmarsh and mangrove in Yueqing Bay, China," Science of The Total Environment.

[20] Z. Ouyang, M. Zhang, X. Xie, Q. Shen, H. Guo, and Q. Zhao, "A comparison of pixel-based and object-oriented approaches to VHR imagery for mapping saltmarsh plants," Ecological Informatics, vol. 6, no. 2, pp. 136-146, 2011.

[21] E. R. DeLancey, J. Kariyeva, J. T. Bried, and J. N. Hird, "Largescale probabilistic identification of boreal peatlands using Google Earth Engine, open-access satellite data, and machine learning," PLoS One, vol. 14, no. 6, article e0218165, 2019.

[22] A. Wang, J. Chen, C. Jing et al., "Monitoring the invasion of Spartina alterniflora from 1993 to 2014 with Landsat TM and SPOT 6 satellite data in Yueqing Bay, China," PLoS One, vol. 10, no. 8, article e0135538, 2015.

[23] X. Zhu, L. Meng, Y. Zhang, Q. Weng, and J. Morris, “Tidal and meteorological influences on the growth of invasive Spartina alterniflora: evidence from UAV remote sensing," Remote Sensing, vol. 11, no. 10, p. 1208, 2019.

[24] J. N. Hird, E. R. DeLancey, G. J. McDermid, and J. Kariyeva, "Google Earth Engine, open-access satellite data, and machine 
learning in support of large-area probabilistic wetland mapping," Remote Sensing, vol. 9, no. 12, p. 1315, 2017.

[25] H. Wan, Q. Wang, D. Jiang, J. Fu, Y. Yang, and X. Liu, "Monitoring the invasion of Spartina alterniflora using very high resolution unmanned aerial vehicle imagery in Beihai, Guangxi (China)," The Scientific World Journal, vol. 2014, Article ID 638296, 7 pages, 2014.

[26] J. E. Vogelmann, A. L. Gallant, H. Shi, and Z. Zhu, "Perspectives on monitoring gradual change across the continuity of Landsat sensors using time-series data," Remote Sensing of Environment, vol. 185, pp. 258-270, 2016.

[27] S. Huang, Y. Chen, and Y. Li, "Spatial dynamic patterns of saltmarsh vegetation in southern Hangzhou Bay: exotic and native species," Water Science and Engineering, vol. 13, no. 1, pp. 34$44,2020$.

[28] M. Liu, D. Mao, Z. Wang et al., "Rapid invasion of Spartina alterniflora in the coastal zone of mainland China: new observations from Landsat OLI images," Remote Sensing, vol. 10, no. 12, p. 1933, 2018.

[29] C. Sun, Y. Liu, S. Zhao, M. Zhou, Y. Yang, and F. Li, “Classification mapping and species identification of salt marshes based on a short-time interval NDVI time-series from HJ-1 optical imagery," International Journal of Applied Earth Observation and Geoinformation, vol. 45, pp. 27-41, 2016.

[30] Z. Zheng, Y. Zhou, B. Tian, and X. Ding, "The spatial relationship between salt marsh vegetation patterns, soil elevation and tidal channels using remote sensing at Chongming Dongtan nature reserve, China," Acta Oceanologica Sinica, vol. 35, no. 4, pp. 26-34, 2016.

[31] V. J. Pasquarella, C. E. Holden, L. Kaufman, and C. E. Woodcock, "From imagery to ecology: leveraging time series of all available Landsat observations to map and monitor ecosystem state and dynamics," Remote Sensing in Ecology and Conservation, vol. 2, no. 3, pp. 152-170, 2016.

[32] S. Foga, P. L. Scaramuzza, S. Guo et al., "Cloud detection algorithm comparison and validation for operational Landsat data products," Remote Sensing of Environment, vol. 194, pp. 379390, 2017.

[33] A. Campbell and Y. Wang, "Examining the influence of tidal stage on salt marsh mapping using high-spatial-resolution satellite remote sensing and topobathymetric LiDAR," IEEE Transactions on Geoscience and Remote Sensing, vol. 56, no. 9, pp. 5169-5176, 2018.

[34] A. D. Campbell and Y. Wang, "Salt marsh monitoring along the mid-Atlantic coast by Google Earth Engine enabled time series," PLoS One, vol. 15, no. 2, article e0229605, 2020.

[35] N. Pettorelli, J. O. Vik, A. Mysterud, J. Gaillard, C. J. Tucker, and N. C. Stenseth, "Using the satellite-derived NDVI to assess ecological responses to environmental change," Trends in Ecology \& Evolution, vol. 20, no. 9, pp. 503-510, 2005.

[36] A. R. Huete, H. Liu, K. Batchily, and W. van Leeuwen, "A comparison of vegetation indices over a global set of TM images for EOS- MODIS," Remote Sensing of Environment, vol. 59, no. 3, pp. 440-451, 1997.

[37] A. Huete, K. Didan, T. Miura, E. P. Rodriguez, X. Gao, and L. G. Ferreira, "Overview of the radiometric and biophysical performance of the MODIS vegetation indices," Remote Sensing of Environment, vol. 83, no. 1-2, pp. 195213, 2002.

[38] S. K. McFeeters, "The use of the Normalized Difference Water Index (NDWI) in the delineation of open water features,"
International Journal of Remote Sensing, vol. 17, no. 7, pp. 1425-1432, 1996.

[39] H. Xu, "Modification of normalised difference water index (NDWI) to enhance open water features in remotely sensed imagery," International Journal of Remote Sensing, vol. 27, no. 14, pp. 3025-3033, 2006.

[40] G. L. Feyisa, H. Meilby, R. Fensholt, and S. R. Proud, "Automated water extraction index: a new technique for surface water mapping using Landsat imagery," Remote Sensing of Environment, vol. 140, pp. 23-35, 2014.

[41] L. Liu, B. Song, S. Zhang, and X. Liu, "A novel principal component analysis method for the reconstruction of leaf reflectance spectra and retrieval of leaf biochemical contents," Remote Sensing, vol. 9, no. 11, p. 1113, 2017.

[42] L. Liu, S. Zhang, and B. Zhang, "Evaluation of hyperspectral indices for retrieval of canopy equivalent water thickness and gravimetric water content," International Journal of Remote Sensing, vol. 37, no. 14, pp. 3384-3399, 2016.

[43] X. Xiao, S. Boles, S. Frolking et al., "Mapping paddy rice agriculture in South and Southeast Asia using multi- temporal MODIS images," Remote Sensing of Environment, vol. 100, no. 1, pp. 95-113, 2006.

[44] B. Chen, X. Xiao, X. Li et al., "A mangrove forest map of China in 2015: analysis of time series Landsat 7/8 and sentinel-1A imagery in Google Earth Engine cloud computing platform," ISPRS Journal of Photogrammetry and Remote Sensing, vol. 131, pp. 104-120, 2017.

[45] Z. Zou, J. Dong, M. A. Menarguez et al., "Continued decrease of open surface water body area in Oklahoma during 19842015," Science of the Total Environment, vol. 595, pp. 451460, 2017.

[46] Z. Zou, X. Xiao, J. Dong et al., "Divergent trends of opensurface water body area in the contiguous United States from 1984 to 2016," Proceedings of the National Academy of Sciences of the United States of America, vol. 115, no. 15, pp. 3810-3815, 2018.

[47] Y. Shi-lun and C. Ji-yu, "Coatal salt marshes and mangrove swamps in China," Chinese Journal of Oceanology and Limnology, vol. 13, no. 4, pp. 318-324, 1995.

[48] H. Chen, "Spartina resources and its usage in the intertidal zone in North Jiangsu province," Natural Resources, vol. 6, pp. 56-63, 1990.

[49] C. Chung, R. Zhuo, and G. Xu, "Creation of Spartina plantations for reclaiming Dongtai, China, tidal flats and offshore sands," Ecological Engineering, vol. 23, no. 3, pp. 135-150, 2004.

[50] X. Lu, Y. Huang, J. Hong, D. Zeng, and L. Yang, "Spatial and temporal variations in wetland landscape patterns in the Yellow River Delta based on Landsat images," China Environmental Science, vol. 38, no. 11, pp. 4314-4324, 2018.

[51] W. Wu, B. Tian, Y. Zhou, M. Shu, X. Qi, and W. Xu, "The trends of coastal reclamation in China in the past three decades," Acta Ecologica Sinica, vol. 36, no. 16, pp. 50075016, 2016.

[52] M. Ye, J. Li, X. Shi et al., "Spatial pattern change of the coastline development and utilization in Zhejiang from 1990 to 2015," Geographical Research, vol. 36, no. 6, pp. 1159-1170, 2017.

[53] Q. Wang, The Dynamics of Plant Community Distribution of the Salt Marshes in the Yangtze River Estuary as Influenced by Spartina Alterniflora Invasions, [Ph.D. thesis], Fudan University, Shanghai, China, 2007. 
[54] D. Guan, Ecosystem and Management of Spartina Salt Marsh in Coastal Wetlands of China, Oceanpress, Beijing, China, 2009.

[55] Q. Lin, Study on Landscape Ecological Evolution and Ecosystem Health Assessment of Liaohe Estuarine Wetland, [M.S. thesis], Dalian University of Technology, Dalian, China, 2009.

[56] C. Yao, H. Yuan, X. Meng, and S. Li, "Natural factors for deterioration of coastal wetland in the yellow river delta," Marine Geology \& Quaternary Geology, vol. 31, no. 1, pp. 43-50, 2011.

[57] B. Pan, Study on the Influence of Water and Sediment in the Yellow River on the Delta Front, [M.S. thesis], Shandong Normal University, Jinan, China, 2017.

[58] W. Wei, Z. Tang, Z. Dai, Y. Lin, Z. Ge, and J. Gao, "Variations in tidal flats of the Changjiang (Yangtze) estuary during 1950s2010s: Future crisis and policy implication," Ocean \& Coastal Management, vol. 108, pp. 89-96, 2015.

[59] X. Lu, J. Zhang, J. Hong, and L. Wang, "Analysis of wetland landscape evaluation and its driving factors in Yellow River Delta based on remote sensing image," Transactions of the Chinese Society of Agricultural Engineering, vol. 32, no. S1, pp. 214-223, 2016.

[60] K. Zhang, B. C. Douglas, and S. P. Leatherman, "Global warming and coastal erosion," Climatic Change, vol. 64, no. 1/2, pp. 41-58, 2004.

[61] Z. Chen, Ecological Impacts of the Introduced Spartina Alterniflora Invasions in the Coastal Ecosystems of Chongming Dongtan, the Yangtze River Estuary, [Ph.D. thesis], Fudan University, Shanghai, China, 2004.

[62] Y. Wang, "Sea-level changes, human impacts and coastal responses in China," Journal of Coastal Research, vol. 14, no. 1, pp. 31-36, 1998.

[63] T. Spencer, M. Schuerch, R. J. Nicholls et al., "Global coastal wetland change under sea-level rise and related stresses: the DIVA wetland change model," Global and Planetary Change, vol. 139, pp. 15-30, 2016.

[64] Q. Wang, C. Wang, B. Zhao et al., "Effects of growing conditions on the growth of and interactions between salt marsh plants: implications for invasibility of habitats," Biological Invasions, vol. 8, no. 7, pp. 1547-1560, 2006. 